\title{
MOOCs as disruptive technologies: strategies for enhancing the learner experience and quality of MOOCs
}

\author{
Los MOOC como tecnologías disruptivas: estrategias para mejorar la \\ experiencia de aprendizaje y la calidad de los MOOC.
}

\author{
Gráinne Conole \\ Bath Spa University, United Kingdom \\ grainne.conole@1e.ac.uk
}

\begin{abstract}
This chapter considers the pedagogies associated with different types of Massive Open Online Courses (MOOCs). It argues that the current discourse around the concept of xMOOCs (primarily based around interaction with content and essentially adopting a behaviourist learning approach), and cMOOCs (which focus on harnessing the power of social media and interaction with peers, adopting a connectivist learning approach), is an inadequate way of describing the variety of MOOCs and the ways in which learners engage with them. It will provide a brief history of the emergence of MOOCs and the key stakeholders. It will introduce an alternative means of categorising MOOCs, based on their key characteristics. It will then describe the 7Cs of Learning Design framework, which can be used to design more pedagogically informed MOOCs, which enhances the learner experience and ensure quality assurance.
\end{abstract}

Key words

Massive Open Online Courses, MOOCs, Pedagogies, xMOOCs, cMOOCs, Learning Design, 7Cs.

\begin{abstract}
Resumen
Este trabajo estudia las pedagogías asociadas con los diferentes tipos de Cursos Online Masivos y Abiertos (MOOCs por sus siglas en inglés: Massive Open Online Courses). Se argumenta que el discurso actual sobre el concepto de xMOOCs (basado principalmente en torno a la interacción con el contenido y la adopción esencialmente de un enfoque de aprendizaje conductista) y cMOOCs (que se centran en aprovechar el poder de los medios sociales y la interacción con los compañeros, con la adopción de un enfoque de aprendizaje conectivista), es una forma inadecuada de describir los tipos de MOOCs y las modalidades en las que los estudiantes se involucran con ellos. Se proporcionará una breve historia de la aparición de los MOOCs y la descripción de los actores principales. Se introducirá una forma alternativa de categorizar los MOOCs, en función de sus características clave. Luego, se describirá el modelo de las 7Cs para el diseño de aprendizaje, que puede ser utilizado para diseñar MOOCs con criterios más pedagógicos, lo que mejorará la experiencia del estudiante y asegurará la garantía de calidad.
\end{abstract}

\section{Palabras clave}

Cursos Online Masivos y Abiertos, MOOCs, Pedagogías, xMOOCs, cMOOCs, Diseño de Aprendizaje, 7Cs.

\section{Introduction}

Every few years a new disruptive technology emerges, i.e. something that fundamentally changes the way we do things (Christensen 1997). The Internet, mobile 
devices and even Virtual Learning Environments are all examples. With the Internet, institutions moved from communication through paper memos to ubiquitous use of email, similarly all departments have a web presence, both to promote the department's activities generally and to have at least some presence in terms of course offerings. Mobile phones have made landlines virtually redundant; and the functionality of today's smart phones means that they are used for far, far more things than simply making a phone call. Virtual Learning Environments made institutions realise that technologies were an essential part of the service they offered students. They enabled teachers to upload content and provide mechanisms for students to communicate and collaborate via tools such as forums, blogs and wikis.

The latest in the line of disruptive technologies is Massive Open Online Courses (MOOCs). Initiated by the Connectivism and Connective Knowledge course created by Siemen's et al. in 2008 (Wikipedia 2012), the number of MOOCs have proliferated in recent years. Indeed there isn't a Vice Chancellor or Rector in the world who isn't considering what the impact of these free online courses might have on traditional educational offerings. Martin Bean (Vice Chancellor of the Open University UK), talking about the announcement of FutureLearn, ${ }^{1}$ stated:

In 2012 that wave of disruption hit higher education. By the end of the year, 18 of the top 20 universities in North America were offering MOOCs - so that's the "great brands" box ticked (Bean 2013).

However, MOOCs have generated heated debate; opinions are divided about their value and importance. Some argue that they open up access to education and hence foster social inclusion, others cynically suggest that they are merely a marketing exercise more about 'learning income than learning outcomes' and point to the phenomenally high drop out rates (typically between $95-98 \%)^{2}$

This chapter will summarise some of the key discourses around MOOCs. It will describe the way in which they are being characterised as either xMOOCs or cMOOCs, but will suggest that this distinction is too limiting. It will put forward a categorisation that can better describe the nuances of different types of MOOCs and will demonstrate how this framework, along with new approaches to designing, through use of a Learning Design framework (the 7Cs of Learning Design) can be use to create more pedagogically effective MOOCs, which will enhance the learning experience and lead to quality enhancement of these types of courses (Conole 2012; Conole 2013).

\section{The learner experience and quality enhancement}

Before discussing MOOCs, it is worth reflecting on what characterises good learning. An understanding of this will help frame the extent to which these facets of learning are realised in MOOCs and how they underpin the proposed framework described in this chapter for providing a more quality assured approach to the design of MOOCs.

\footnotetext{
${ }^{1}$ http://futurelearn.com/

2 For a debate on the pros and cons see the video of ASCILITE's 'The great MOOC debate' http://alternative-educate.blogspot.co.uk/2012/12/audio-ascilite-2012-great-debate-moocs.html
}

MOOCs as disruptive technologies: strategies for enhancing the learner experience and quality of MOOCs. Gráinne Conole 


\section{The nature of learning and the learner experience}

Research into what constitutes good learning goes back to Dewey and beyond (Dewey 1916; Biggs 1999; Brown 2001; Thorpe 2002; Jarvis 2004; Sawyer 2006). More recently, there has been a substantial body of research exploring learners' experience of and perceptions about technology (Oblinger and Oblinger 2005; Borgeman, Abelson et al. 2008; De Freitas and Conole 2010; Sharpe and Beetham 2010). ${ }^{3}$ This research indicates that today's learners are technologically immersed and see technologies as an essential tool for learning, they use a variety of strategies for findings and collating resources and for communicating and collaborating with peers. In essence, the characteristics of good learning (Conole 2013) are that it:

- Encourages reflection

- Enables dialogue

- Fosters collaboration

- Applies theory learnt to practice

- Creates a community of peers

- Enables creativity

- Motivates the learners.

Technologies offer many ways in which these can be realised; through interaction with multimedia, and through communication and collaboration with peers (Traxler 2005; Conole and Alevizou 2010; Childs and Peachey 2011; Rennie and Morrison 2012). Technologies can be used to foster different pedagogical approaches, which can be characterised as: associative, constructivist, situative and connectivist (Conole, Dyke et al. 2004; Mayes and De Freitas 2004; Conole 2010).

\section{Defining quality}

There are a number of general teaching and learning national quality agencies. Specifically, in relation to quality and e-learning, EFQUEL ${ }^{4}$ is Europe's professional body for quality in e-learning. EFQUEL's mission 'to promote excellence and innovation in education in order to achieve qualitative learning opportunities in Europe and beyond'. 5

A fundamental aspect of ensuring a good learner experience is the quality of the course. It is important to distinguish between three main aspects of quality: quality audit, quality assurance and quality enhancement.

In general quality can be defined as 'the standard of something as measured against other things of a similar kind; the degree of excellence of something: quality of life'. 6

\footnotetext{
${ }^{3}$ See also the JISC Learning Experience Programme (http://www.jisc.ac.uk/whatwedo/programmes/elearningpedagogy/learnerexperience.aspx) rome.0.59j57j0l2j60j62.4758j0\&sourceid=chrome\&ie=UTF-8\#sclient=psy-

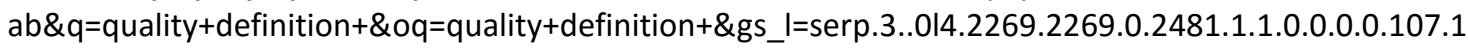
07.0j1.1.0...0.0...1c.1.14.psy-
}

MOOCs as disruptive technologies: strategies for enhancing the learner experience and quality of MOOCs. Gráinne Conole 
Therefore arguably quality in e-learning is the degree to which it measure up to 'good learning' (although that might be construed as a somewhat contentious statement). It certainly points to the notion of excellence and worth.

Quality assurance mechanisms are now requirements in most formal educational institutions and indeed many countries have a requirement for institutions to undergo externally reviewed quality audits on a regular basis. Institutional quality audit aims 'to contribute, in conjunction with other mechanisms, to the promotion and enhancement of high-quality in teaching and learning'.

The Quality Assurance Agency in the UK describes quality assurance as 'the means through which an institution ensures and confirms that the conditions are in place for students to achieve the standards set by it or by another awarding body' (QAA 2004), and quality enhancement as 'the process of taking deliberate steps at institutional level to improve the quality of learning opportunities.... Quality enhancement is therefore seen as an aspect of institutional quality management that is designed to secure, in the context of the constraints within which individual institutions operate, steady, reliable and demonstrable improvements in the quality of learning opportunities' (QAA 2006). The EvidenceNet web page ${ }^{8}$ from which these terms were taken, provides a diagram, which suggests that the two terms are in opposition (Figure 1).

ab.oVQgVsASSAQ\&pbx=1\&bav=on.2,or.r_cp.r_qf.\&bvm=bv.46751780,d.d2k\&fp=13e85b7e7d899dc\&bi $w=853 \&$ bih $=343$

${ }^{7}$ http://www.qaa.ac.uk/Publications/InformationAndGuidance/Documents/eLearning.pdf

${ }^{8}$ http://evidencenet.pbworks.com/ 


\begin{tabular}{|c|c|}
\hline Quality Assurance & Quality Enhancement \\
\hline Focus on teaching & Focus on learning \\
\hline Teaching as individual "performance" & Learning as "social practice" \\
\hline Focus on monitoring / judgement & Focus on professional development \\
\hline $\begin{array}{l}\text {-Top down" implementation by } \\
\text { managers not active in teaching }\end{array}$ & $\begin{array}{l}\text { Active engagement of senior staff and } \\
\text { teachers during implementation }\end{array}$ \\
\hline $\begin{array}{l}\text { Inflexible, non-negotiable approach } \\
\text { based on "standards" }\end{array}$ & $\begin{array}{l}\text { Flexible context-sensitive approach } \\
\text { based on building professional } \\
\text { knowledge }\end{array}$ \\
\hline $\begin{array}{l}\text { Little acknowledgement of the link } \\
\text { between teaching and research }\end{array}$ & $\begin{array}{l}\text { Seeks to establish links between } \\
\text { teaching and research, through } \\
\text { reflection on practice }\end{array}$ \\
\hline $\begin{array}{l}\text { May undermine professional } \\
\text { autonomy through monitoring and } \\
\text { surveillance activity }\end{array}$ & $\begin{array}{l}\text { Respects and values professional } \\
\text { autonomy }\end{array}$ \\
\hline $\begin{array}{l}\text { Focuses on the teacher as individual } \\
\text { practitioner }\end{array}$ & $\begin{array}{l}\text { Seeks to increase collaboration } \\
\text { between teachers and across } \\
\text { disciplines }\end{array}$ \\
\hline Emphasis on documentation & Emphasis on discussion \\
\hline
\end{tabular}

\section{Figure 1: Comparing the focus of quality assurance and quality enhancement}

However, Raban (2007) argues that the two are not in opposition, suggesting that we need to seek innovation and enhancement of learning:

The improvement of teaching and learning and the dissemination of good practice are important; and conventional approaches to quality management can provide the intelligence and stimulus for this kind of enhancement. But these approaches are not conducive to more fundamental action on the deeper institutional factors that impact on teaching and learning; nor are they conducive to the promotion of innovative (and risk-taking) practice and the creation of new curricular and organisational structures. For this we require a 'modernisation' of our quality assurance systems that would facilitate risk-taking and anticipate its possible consequences.

This statement is of particular importance in relation to the increased use of technologies; clearly there are benefits as outlined earlier and mechanisms of promoting innovation, but equally there are risk associated. MOOCs are a prime example of this, on the one hand they offer an innovative, potentially exciting educational experience,

MOOCs as disruptive technologies: strategies for enhancing the learner experience and quality of MOOCs. Gráinne Conole 
which promotes social inclusion, on the other hand there are dangers is terms of a detrimental learner experience through bad design.

Ehlers et al. (Ehlers, Ossiannilsson et al. 2013) argue that quality is very much the condition which determines how effective and successful learning can take place.

They go on to pose the following questions in relation to the quality of MOOCs:

- What are MOOCs actually aiming at?

- Can the quality of MOOCs be assessed in the same way as any defined university course with traditional degree awarding processes? Or do we have to take into account a different type of objective with MOOC learners?

- Are the learners mostly interested in only small sequences of learning, tailored to their own individual purpose, and then sign off and move to other MOOCs because their own learning objective was fulfilled?

Discussing MOOCs and quality, Downes argues that:

When we are evaluating a tool, we evaluate it against its design specifications; mathematics and deduction tell us from there that it will produce its intended outcome. It is only when we evaluate the use of a tool that we evaluate against the actual outcome. So measuring drop-out rates, counting test scores, and adding up student satisfaction scores will not tell us whether a MOOC was successful, only whether this particular application of this particular MOOC was successful in this particular instance (Downes 2013).

Therefore quality is a fundamental facet that needs to be considered in relation to both the design and delivery of MOOCs. We need to develop better metrics to understand the way in which learners are interacting with MOOCs and hence their experience of them.

\section{The importance of good learning and enhancing the quality of the learner experience}

This section has described both the characteristics of good learning and the concept and importance of quality. Both need to be considered in conjunction to enhance the quality of the learner experience. Whilst mechanisms to ensure this are well established in formal education institutions, such mechanisms are not in place, certainly not in any formal sense, for MOOCs. And arguably this is a key issue that needs to be address if MOOCs are going to valuable and viable learning experiences and be sustainable in the longer term.

\section{Massive Open Online Courses (MOOCs)}

This section will begin by defining MOOCs and providing a brief description of their emergence. Key stakeholders will be described, along with the perceived benefits and challenges associated with MOOCs. The types of MOOCs will be discussed and a new classification framework for distinguishing different types of MOOCs will be introduced.

MOOCs as disruptive technologies: strategies for enhancing the learner experience and quality of MOOCs. Gráinne Conole 


\section{A brief history of MOOCs \\ MOOCs have been defined as:}

A massive open online course (MOOC) is an online course aimed at large-scale interactive participation and open access via the web. In addition to traditional course materials such as videos, readings, and problem sets, MOOCs provide interactive user forums that help build a community for the students, professors, and TAs (Teaching Assistants) (Wikipedia 2012).

The acronym highlights the key components; i.e. that they are online courses which harness the potential for learning in a large-scale, distributed community of peers, through open practices.

Much has been written about the emergence of MOOCs as a phenomenon, these are not listed here, but for an up to date account of MOOC research, there are two recent special issues which point to much of the literature in the field, ${ }^{9}$ and at the time of writing there is a call out for a special issue of Distance Education. ${ }^{10}$ Siemens et al. created the first MOOC in 2008, called 'Connectivism and Connective Knowledge'. The course was based on a connectivist pedagogy, which aimed to foster the affordances of social and participatory media. It relied on the benefits of scale though significant interaction with a distributed network of peers. Participants were encouraged to use a variety of technologies; to reflect on their learning and to interact with others. There was no 'right way' through the course; the emphasis was on personalised learning through a personal learning environment. Variants on this course emerged, collectively known as cMOOCs, examples included: David Wiley's course on 'Open Education', 'Personal Learning Environments and Networks (CCK11)', ${ }^{12}$ and 'Learning Analytics (LAK12)'.'

A second type of MOOC emerged in 2011, namely xMOOCs. These were primarily based on interactive media, such as lectures, videos and text. xMOOCs adopted a more behaviourist pedagogical approach, with the emphasis on individual learning, rather than learning through peers. As a result a number of companies emerged, such as: Audacity, ${ }^{14} \mathrm{EdX},{ }^{15}$ and Coursera. ${ }^{16}$ These courses tend to be offered by prestigious institutions, such as Harvard and Stanford, the emphasis is on delivery of content via professors from these institutions.

Nkuyubwatsi provides a useful overview of MOOCs, including a review of some of the key courses from 2008 to the present day (Nkuyubwatsi 2013). He discusses the key controversy around MOOCs, stating that MOOCs are hailed for their fit within a knowledge society, providing each learner with opportunities to engage with material

\footnotetext{
${ }^{9}$ http://elearningyork.wordpress.com/2013/05/14/elearning-papers-special-moocs-and-beyond/ and http://ispr.info/2012/10/26/call-massive-open-online-courses-moocs-special-issue-of-journal-of-onlinelearning-and-teaching-jolt/ (due out late 2013).

${ }^{10}$ http://www.tandf.co.uk/journals/cfp/cdiecfp.pdf

${ }^{11}$ https://learn.canvas.net/courses/4

12 http://cck11.mooc.ca/

${ }^{13}$ http://lak12.mooc.ca/

${ }^{14}$ https://www.udacity.com/

${ }^{15}$ https://www.edx.org/

${ }^{16}$ https://www.coursera.org/
}

MOOCs as disruptive technologies: strategies for enhancing the learner experience and quality of MOOCs. Gráinne Conole 
via formative assessments and the ability to personalise their learning environment. However, he goes on to state that they are criticised for the lack of constructive feedback and the lack of creative and original thinking, citing Bates (2012) and low completion rates, citing Daniel (2012).

\section{Pedagogical approaches}

Participation in MOOCs can range from informal non-accredited participation through to engagement as part of a formal course offering. In some instances, tuition-paying students taking courses for credit join the same class as non-tuition paying, non-credit learners.

Many xMOOCs are primarily based on interactive material and videos plus multiplechoice quizzes. Udacity, Coursera and EdX courses consist mainly of lecture videos, course materials, quizzes and assignments. Some do contain wikis and discussion forums, although these are not extensively promoted or used. In some cases forum posts can be up- or down-voted by other participants; if a post is up-voted that participant receives a 'karma point'. For some Udacity courses, participants have organized their own meet-ups with others who are Geographically co-located. Udacity has set up a meet-up site to facilitate this.

Cormier, in a video describing the nature of Connectivist MOOCs, ${ }^{17}$ defines five steps to success: orient, declare, network, cluster and focus. He also argues that knowledge in a MOOC is emergent and dependent on the interaction with others. In his PLENK2010 course he defines four types of activities: aggregate, remix, repurpose and feed forward. Therefore the intention of cMOOCs is to harness the power of social and participatory media to enable participants to communicate and collaborate through a variety of channels; for example Twitter, blogs, wikis, etc. and the use hashtags and curation tools (such as Pinterist or Scoop.it) to filter and aggregate. The focus is on personalisation, but also collective intelligence (Lévy 1997). Each participate forges their own learning path through the materials; picking and mixing which content, activities and communications are meaningful for them. These types of course align well with Cormier's notion of Rhizomatic learning (Cormier 2008; Cormier 2011), i.e. networks are horizontal, dynamic and emergent, developing in different directions for different individuals. Barry provides a nice comparison of three different MOOCs in terms of workload, technology, content, pedagogy, assessment, etc. (Barry 2013).

Assessment models for MOOCs vary, from simple Multiple Choice responses, through to peer-reviewed feedback and more formal, traditional modes of assessment. DS106, ${ }^{18}$ adopted an interesting approach to assessment, whereby course assignments were collectively created by participants and then posted to an assessment bank (EDUCAUSE 2013). Participants could then choose which assignment they wanted to do which were rated on a difficulty of $1-5$. In this model the assessment bank expanded for use by further participants. An interesting recent innovation in terms of assessment is the use of open badges. The concept is simple; learners can apply for badges demonstrating their completion of aspects of a MOOC. This may be as simple as completion of part of the course or evidence of particular aspects of learning. Badges have criteria associated with them; learners are expected to demonstrate how they have achieved these criteria and this is validated either by peers or tutors. The Mozilla's

\footnotetext{
${ }^{17} \mathrm{http}: / /$ www.youtube.com/watch?v=eW3gMGqcZQc

${ }^{18} \mathrm{http}: / /$ ds106.us/
}

MOOCs as disruptive technologies: strategies for enhancing the learner experience and quality of MOOCs. Gráinne Conole 
Open Badges, ${ }^{19}$ are perhaps the best known examples of badges. Their slogan is 'Get recognition for skills you learn anywhere'. There are three parts to the process: earn (earn badges for skills you learn online and off), issue (get recognition for things you teach) and display (show your badges on the places that matter).

Therefore there are a variety of different pedagogical approaches being adopted in different MOOCs, some emphisising individual learning through interactive materials, others focusing more on social learning.

\section{Stakeholders}

The stakeholders for MOOCs are essentially learners (in terms of participating in the MOOCs, tutors (if there are any - in terms of facilitating the MOOCs), teachers (in terms of designing and assessing the MOOCs), institutional managers (in terms of considering their place alongside traditional educational offerings), policy makers (in terms of thinking of the longer term implications for the educational landscape) and venture capitalists (looking to get a return on investment).

Arguably the origin of MOOCs was bottom up; developed by individuals with a vision for promoting open educational practices ${ }^{20}$ and fostering connectivist learning approaches through use of social and participatory media. However the recent emergence of start-ups, like Audacity, and initiatives like FutureLearn suggest a shift to a more top down structured approach. Coupled with this, there is evidence of an increase in the notion of open education at policy debate. For example, in December 2012, the Opening up Education through Technologies conference was held in Oslo. The conference was aimed at ministers of education across Europe, to inform them of current thinking on openness and the implications for policy. UNESCO has long being a promoted of Open Educational Resources, stating that:

UNESCO believes that universal access to high quality education is key to the building of peace, sustainable social and economic development, and intercultural dialogue. Open Educational Resources (OER) provide a strategic opportunity to improve the quality of education as well as facilitate policy dialogue, knowledge sharing and capacity building. ${ }^{21}$

Whether there is a tension between the grass roots initiatives and the more structured approaches remains to be seen.

The plethora of MOOCs now available, in a variety of languages (although the majority are still in English), is staggering. Recent examples include: the announcement in the UK of FutureLearn (with 21 UK institutions), Open2Study from the Open University of Australia and the EU-based OpenUpEd.

\footnotetext{
${ }^{19}$ dougbelshaw.com/blog/2012/07/19/informal-learning-gaming-and-openbadgesdesign/\#.UAviyURJH40

${ }^{20}$ Open Educational Practices (OEP) were first defined in relation to the creation, management and repurposes of Open Educational Resources (OER) as part of the OPAL initiative (http://www.oerquality.org/), i.e. a focus on how OER are being used rather than their production per se. The notion has seen been expanded to cover other facets of Open Education, including MOOCs. Therefore I would argue OEP relate to adopting more open practices in educational contexts.

${ }^{21} \mathrm{http}$ ://www.unesco.org/new/en/communication-and-information/access-to-knowledge/openeducational-resources/
}

MOOCs as disruptive technologies: strategies for enhancing the learner experience and quality of MOOCs. Gráinne Conole 


\section{Provide some statistics.}

\section{Classifying MOOCs}

Terminology is always tricky when trying to describe a new disruptive technology. Even the term for the use of technology to support learning is contested and various terms have been used over the years: educational technology, learning technology, networked learning, Technology-Enhanced Learning, etc. (Conole and Oliver 2007). MOOCs can be seen along a spectrum of adopting more open education practices; from the concept of Learning Objects (Littlejohn 2003) and more recently Open Educational Resources (Glennie, Harley et al. 2012).

As mentioned earlier, to date, MOOCs have been classified as either xMOOCs or cMOOcs. I want to argue that such a classification is too simplistic and in this section put forward an alternative mechanism for describing the nature of MOOCs. Downes suggest four criteria: autonomy, diversity, openness, and interactivity (Downes 2010). Clark (2013) recently provided the follow taxonomy of types of MOOCs:

- transferMOOCs - where existing courses are transferred to a MOOC

- madeMOOCs - which are more innovative, making effective use of video and interactive material and are more quality driven

- $\quad$ synchMOOCs - with a fixed start and end date

- asynchMOOCs - which don't have fixed start and end dates and have more flexible assignment deadlines

- adaptiveMOOCs - which provide personalised learning experiences, based on dynamic assessment and data gathering on the course

- groupMOOCs -where the focus is on collaboration in small groups

- connectivistMOOCS - emphasis on connection across a network of peers

- miniMOOCSs - which are much smaller than the traditional massive MOOC

Reich asked the question is a MOOC a textbook or a course (Reich 2013)? He suggests that even the notion of a course is contentious, with parameters such as: start/end dates, self-paced or directed learning, skills or content based, the nature of interactions and whether or not certification is included. He suggests there are two analogies for MOOCs; as books or courses. I think these analogies are flawed. Learning occurs along a spectrum from informal to formal; from loosely based resource-based learning to a structured, time-defined course, which is accredited. MOOCs, in my view, can fit along any point of this spectrum; i.e. they can be used by individuals to support informal learning, where learners might not complete all of the MOOC, but instead dip into different aspects - through to receiving full accreditation and being part of an institutional provided formal course.

I want to suggest that a better classification of MOOCs is in terms of a set of twelve dimensions: the degree of openness, the scale of participation (massification), the amount of use of multimedia, the amount of communication, the extent to which collaboration is included, the type of learner pathway (from learner centred to teachercentred and highly structured), the level of quality assurance, the extent to which reflection is encouraged, the level of assessment, how informal or formal it is, autonomy, and diversity. MOOCs can then be measured against these twelve

MOOCs as disruptive technologies: strategies for enhancing the learner experience and quality of MOOCs. Gráinne Conole 
dimensions (Table 1). The following MOOCs are shown to illustrate how different MOOCs map to these ten dimensions:

1. Connectivism and Connective Learning 2011 (CCK). ${ }^{22}$ The course took part over twelve weeks. The course uses a variety of technologies, for example, blogs, Second Life, RSS Readers, UStream, etc. Course resources were provided using gRSShopper and online seminars delivered using Elluminate. Participants were encouraged to use a variety of social media and to connect with peer learners, creating their own Personal Learning Environment and network of colearners.

2. Introduction to Artificial Intelligence (AI) 2011 (CS221). ${ }^{23}$ The course ran over three months and included feedback and a statement of accomplishment. A small percentage of participants enrolled registered for the campus-based Stanford course. The course was primarily based around interactive multimedia resources. The course is now based on the Audacity platform.

3. OLDS (Learning Design) (OLDS) 2013. ${ }^{24}$ The course ran over eight weeks, with a ninth reflection week. It was delivered using Google Apps, the main course site being built in Google Drive, Google forums and Hangouts were also used. Cloudworks ${ }^{25}$ was used as a space for participants to share and discuss their course artefacts and to claim credit for badges against course achievements.

4. Openness and innovation in elearning (H817). ${ }^{26}$ The course is part of the Masters in Open and Distance Education offered by the Open University UK. H817 runs between February and October 2013 months, however the MOOC component of the course consists of 100 learning hours spread over seven weeks from March 2013 and is open to a wider audience than those registered on the OU course. The course adopts an 'activity-based' pedagogy. There is an emphasis on communication through blog postings and the forum. Participants have the opportunity to acquire badges for accomplishments.

5. Introduction to Openness in Education (OE). ${ }^{27}$ The course tutor advocates that "learning occurs through construction, annotation and maintenance of learning artifacts," which is the philosophy that underpins the design of the course. Participant could acquire badges for various accomplishments.

Table 1: Mapping 5 course to the 10 dimensions of MOOCs

\begin{tabular}{|l|l|l|l|}
\hline Dimension & Low & Medium & High \\
\hline Open & & H817, OE, AI & CCK, OLDS \\
\hline Massive & OLDS, H817, OE & CCK & AI \\
\hline Use of multimedia & & $\begin{array}{l}\text { CCK, } \\
\text { H817, OE }\end{array}$ & OLDS, \\
\hline $\begin{array}{l}\text { Degree of } \\
\text { communication }\end{array}$ & AI & OLDS, H817, OE & CCK \\
\hline Degree of & AI & CCK, OLDS, OE & H817 \\
\hline
\end{tabular}

\footnotetext{
${ }^{22}$ http://cck11.mooc.ca/

${ }^{23}$ https://www.udacity.com/course/cs271

${ }^{24}$ http://www.olds.ac.uk/

${ }^{25}$ http://cloudworks.ac.uk

${ }^{26}$ http://www.open.edu/openlearn/education/open-education/content-section-0

${ }^{27}$ https://learn.canvas.net/courses/4
}

MOOCs as disruptive technologies: strategies for enhancing the learner experience and quality of MOOCs. Gráinne Conole

Página 11 de 18 


\begin{tabular}{|l|l|l|l|}
\hline collaboration & & & \\
\hline Learning pathway & CCK & OLDS, H817, OE & AI \\
\hline Quality Assurance & CCK & AI, OLDS, OE & H817 \\
\hline Amount of reflection & AI & OLDS, OE & CCK \\
\hline Certification & CCK $^{28}$ & OLDS, AI & OE \\
\hline Formal learning & AI, CCK & OLDS & H817, OE \\
\hline Autonomy & & H817, OE & CCK, OLDS, AI \\
\hline Diversity & & H817, AI, OLDS & CCK, OE \\
\hline
\end{tabular}

The table demonstrates that, in terms of the twelve dimensions, the five MOOCs illustrate examples of low, medium and high degrees of each. I would argue that at a glance this classification framework gives a far better indication of the nature of each MOOC than the simple classification as XMOOCs and cMOOCs.

\section{Enhancing the quality of MOOCs through effective design}

Despite the potential of new technologies to support learning, there is a gap between the reality and practice; teachers lack the skills needed to harness the power of new technologies (Conole 2013). In particular, as outlined earlier, many criticise MOOCs, pointing to high drop out rates and learner confusion and frustration. Particularly, with cMOOCs many participants complain that they are confused by the multitude of communication routes. Another common complaint relates to workload, i.e. the actual time required to complete the courses far exceeds the stated time allocation. Critics of xMOOCs argue that they represent a 'step back' pedagogically, re-instantiating didactic learning, which they argue does not translate well into the online learning environment.

The 7Cs of Learning Design framework (Figure 1) aims to provide teachers with the guidance and support they need to make more pedagogically informed design decisions that make effective use of new technologies. It consists of the following elements: Conceptualise (what is the vision for the course?), Capture (a resource audit), Communicate (mechanisms to foster communication), Collaborate (mechanisms to foster collaboration), Consider (assessment strategies), Combine (overarching views of the design), and Consolidate (implementing and evaluating the design in a real learning context). For each $\mathrm{C}$ we have developed a range of resources and tools to guide the teacher through the design process.. These include the Course Features view (Conceptualise), which enables teachers to design a vision for the course in terms of key principles and pedagogical approaches), a resource audit (Capture), mechanisms to foster communication and collaboration (Communicate and Collaborate), assessment strategies, such as ensuring learning outcomes are aligned to assessment elements (Consider), a Course Map view, showing what guidance and support, content and activities, reflection and demonstration, and communication and collaboration are included, along with an activity profile showing the percentage of time learners spend on different types of activities (Combine), and an evaluation rubric for assessing the quality and effectiveness of the design(Consolidate).

\footnotetext{
${ }^{28}$ Although it was possible to obtain certification from the University of Manitoba for completion of the course
}

MOOCs as disruptive technologies: strategies for enhancing the learner experience and quality of MOOCs. Gráinne Conole 


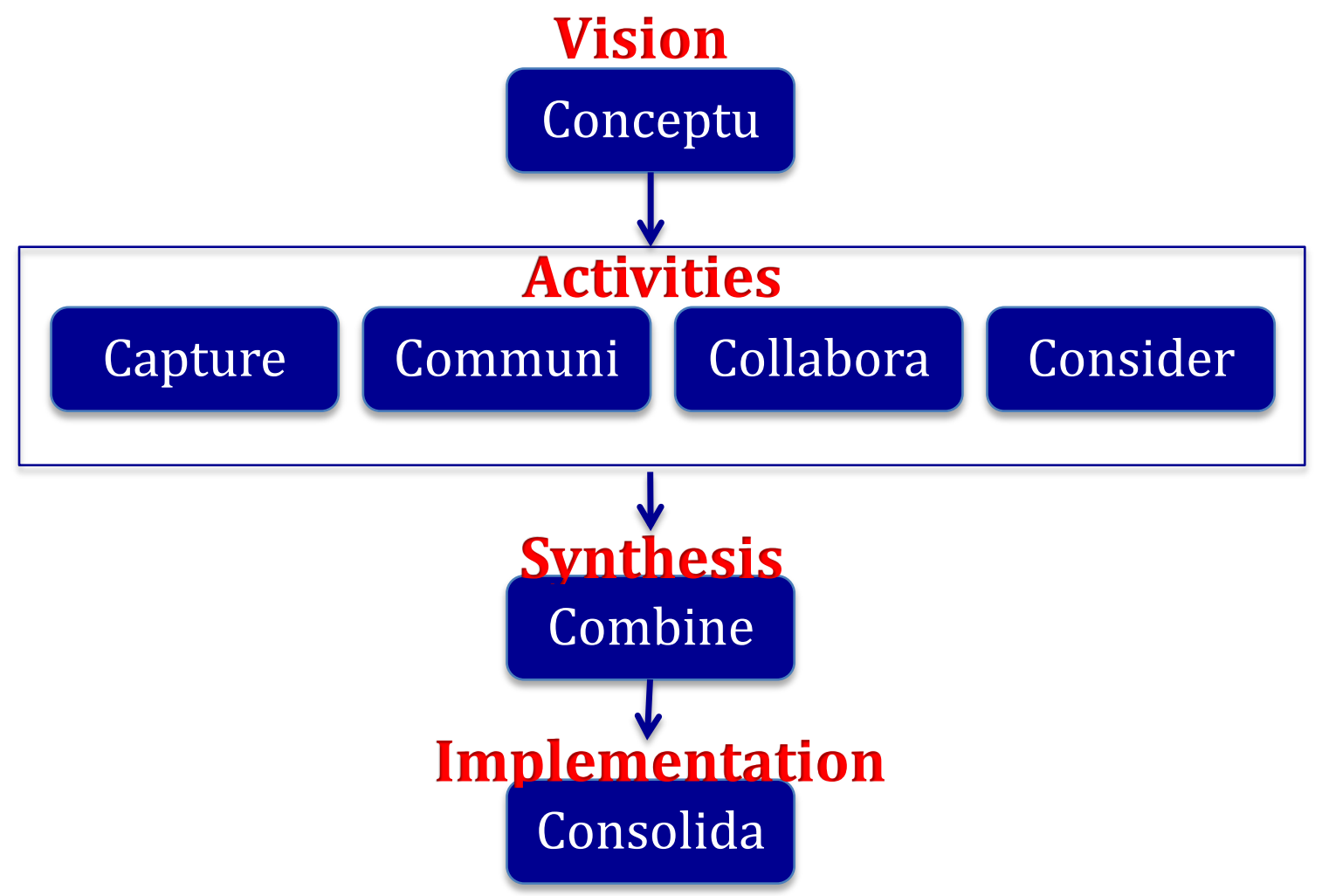

Figure 2: The 7Cs of Learning Design Framework

The MOOC criteria outlined earlier fits under the Conceptualise C. It can be use to plan the design of the MOOC against these twelve criteria. Table 2 shows how these criteria can be used to characterise a Continuing Professional Development course for Medics. The course is informal and is aimed at Medics in a local authority in the UK.

Table 2: Example of using the MOOC criteria in the design of a course

\begin{tabular}{|l|l|}
\hline Dimension & Degree of evidence \\
\hline Open & $\begin{array}{l}\text { High - The course is built using open source tools and } \\
\text { participants are encouraged to share their learning outputs } \\
\text { using the creative commons license. }\end{array}$ \\
\hline Massive & $\begin{array}{l}\text { Low - The course is designed for Continuing Professional } \\
\text { Development for Medics in a local authority. }\end{array}$ \\
\hline Use of multimedia & $\begin{array}{l}\text { High - The course uses a range of multimedia and } \\
\text { interactive media, along with an extensive range of medical } \\
\text { OER. }\end{array}$ \\
\hline communication of & $\begin{array}{l}\text { Medium - The participants are encourage to contribute to a } \\
\text { number of key debates on the discussion forum, as well as } \\
\text { keeping a reflective blog of how the course relates to their } \\
\text { professional practice. }\end{array}$ \\
\hline $\begin{array}{l}\text { Degree } \\
\text { collaboration }\end{array}$ & $\begin{array}{l}\text { Low - The course is designed for busy working } \\
\text { professionals, collaboration is kept to a minimum. }\end{array}$ \\
\hline Learning pathway & $\begin{array}{l}\text { Medium - There are two structured routes through the } \\
\text { course - an advanced and a lite version. }\end{array}$ \\
\hline Quality Assurance & Medium - The course is peer-reviewed prior to delivery. \\
\hline Amount of reflection & \begin{tabular}{l} 
High - Participants are asked to reflect continually during \\
\hline
\end{tabular} \\
\hline
\end{tabular}

MOOCs as disruptive technologies: strategies for enhancing the learner experience and quality of MOOCs. Gráinne Conole 


\begin{tabular}{|l|l|}
\hline Certification & $\begin{array}{l}\text { the course, their personal blogs are particularly important } \\
\text { in this respect. }\end{array}$ \\
\hline Formal learning & $\begin{array}{l}\text { Medium - Participants can obtain a number of badges on } \\
\text { completion of different aspects of the course and receive a } \\
\text { certificate of attendance. }\end{array}$ \\
\hline Autonomy & Low - The course is informal and optional. \\
\hline Diversity & $\begin{array}{l}\text { High - Participants are expected to work individually and } \\
\text { take control of their learning, there is little in the way of } \\
\text { tutor support. }\end{array}$ \\
\hline & $\begin{array}{l}\text { Low - The course is specialised for UK medics in one } \\
\text { local authority. }\end{array}$ \\
\hline
\end{tabular}

The 7Cs framework can be used both to design and evaluate MOOCs. The tools and resources associated with each of the Cs enable the designer to make more informed design decisions. The evaluation rubric under the Consolidate $\mathrm{C}$ enables them to ensure that the design is fit for purpose, hence ensuring the quality of the MOOCs and the ultimate learner experience.

\section{Conclusion}

It is evident that there are a number of drivers impacting on education. Firstly, universities are increasingly looking to expand their online offerings and make more effective use of technologies. Secondly, there is increasing demand from higher student numbers and greater diversity. Thirdly, there is a need to shift from knowledge recall to development of skills to find and use information effectively. In this respect, there is a need to enable learners to develop $21^{\text {st }}$ Century digital literacy skills (Jenkins 2009) to equip them for an increasingly complex and changing societal context. Finally, given the proliferation of new competitors, there is a need for traditional institutions to tackle new competitive niches and business models. ${ }^{29}$ MOOCs represent a sign of the times; they instantiate an example of how technologies can disrupt the status quo of education and are a forewarning of further changes to come. Whether or not MOOCs will reach the potential hype currently being discussed is a mote point, what is clear is that we need to take them seriously. More importantly, for both MOOCs and traditional educational offerings we need to make more informed design decisions that are pedagogically effective, leading to an enhanced learner experience and ensuring quality assurance.

Finally, the key value of MOOCs for me is that they are challenging traditional educational institutions and having to make them think about what they are offering, how it is distinctive and what the unique learner experience will be at their institution. As Cormier states:

When we use the MOOC as a lense to examine Higher Education, some interesting things come to light. The question of the 'reason' for education comes into focus (Cormier 2013).

\footnotetext{
${ }^{29}$ As a recent article states MOOCs are challenging traditional institutional business models http://www.universityworldnews.com/article.php?story=20120831103842302
}

MOOCs as disruptive technologies: strategies for enhancing the learner experience and quality of MOOCs. Gráinne Conole 
Furthermore, UNESCO estimate that more than 100 million children can't afford formal education, ${ }^{30}$ MOOCs provide them with a real lifeline to get above the poverty line. This, and the fact that MOOCs provide access to millions. As Creelman notes:

Whatever you think of them they are opening up new learning opportunities for millions of people and that is really the main point of it all (Creelman 2013).

So for me the value of MOOCs to promote social inclusion, coupled with them making traditional institutions look harder at what they are providing their students, signifies their importance as a disruptive technology. For me therefore, whether they survive or not, if they result in an opening up of education and a better quality of the learner experience that has got to be for the good.

Presentación del artículo: 1 de Noviembre de 2013

Fecha de aprobación: 1 de Diciembre de 2013

Fecha de publicación (en su primera edición): 15 de Diciembre de 2013

Conole, G. (2016). MOOCs as disruptive technologies: strategies for enhancing the learner experience and quality of MOOCs. RED. Revista de Educación a Distancia. 50(2). Consultado el (dd/mm/aaaa) en http://www.um.es/ead/red/50

\section{Bibliografía}

Barry, W. (2013). Comparing the MOOC dot com. The accidental technologist.

Bates, T. (2012). What's wrong and right about Coursera-style MOOCs, . Online learning and distance education resources.

Bean, M. (2013). "FutureLearn." from http://futurelearn.com/feature/interview-withmartin-bean-vice-chancellor-open-university/.

Biggs, J. (1999). "What the student does: teaching for enhanced learning." Higher Education Research \& Development 18(1): 57-75.

Borgeman, C., H. Abelson, et al. (2008). Fostering learning in the networked world: the cyberlearning opportunity and challenge, Report of the NSF task force on cyberlearning.

Brown, J. S. (2001). Learning in the digital age. The Internet and the University: Forum: $71-72$.

Childs, M. and A. Peachey (2011). Reinventing ourselves: contemporary concepts of indentity in Virtual Worlds. New York, Springer.

Christensen, C. (1997). The innovator's dilemma: When new technologies cause great firms to fail. Harvard, Harvard University Press.

\footnotetext{
${ }^{30}$ http://enikki.mitsubishi.or.jp/e/event/index6.html
} 
Clark, D. (2013). MOOCs: taxonomy of 8 types of MOOC. Donald Clark Paln B.

Conole, G. (2010) Review of pedagogical frameworks and models and their use in elearning.

Conole, G. (2012). The 7Cs of design and delivery. e4innovation.com.

Conole, G. (2013). Current thinking on the 7Cs of Learning Design. e4innovation.com.

Conole, G. (2013). Designing for learning in an open world. New York, Springer.

Conole, G. (2013). What is innovative teaching? Invited talk. Royal Holloway, London.

Conole, G. and P. Alevizou (2010) Review of the use(s) of Web 2.0 in Higher Education.

Conole, G., M. Dyke, et al. (2004). "Mapping pedagogy and tools for effective learning design." Computers and Education 43(1-2): 17-33.

Conole, G. and M. Oliver (2007). Contemporary perspectives in e-learning research: themes, methods and impact on practice. London, RoutledgeFalmer.

Cormier, D. (2008). Rhizomatic Education : Community as Curriculum. Dave's educational blog: education, post structuralism and the rise of the machines. http://davecormier.com/edblog/2008/06/03/rhizomatic-education-community-ascurriculum/.

Cormier, D. (2011). Rhizomatic learning - why we teach? Dave's education blog: education, post-structuralism and the rise of the machines. http://davecormier.com/edblog/2011/11/05/rhizomatic-learning-why-learn/.

Cormier, D. (2013). Week 3 - Forget the learners, how do I measure a MOOC quality experience for ME! By Dave Cormier. MOOC Quality Project.

Creelman, A. (2013). Make hay whilt the sunshines. The corridor of uncertainty.

Daniel, J. (2012). "Making sense of MOOCs: Musing in a mazr of myth, paradox and possibility." Journal of Interactive Media in Education 18.

De Freitas, S. and G. Conole (2010). Learners experiences: how pervasive and integrative tools influence expectations of study. Rethinking learning for the digital age: how learnes shape their own experiences. London, Routledge.

Dewey, J. (1916). Experience and Nature. New York, Dover.

Downes, S. (2010). Fairness and equity in education. Huff Post Education.

Downes, S. (2013). Week 2: The Quality of Massive Open Online Courses by Stephen Downes. MOOC Quality Project: perspectives on quality of MOOC-based education.

MOOCs as disruptive technologies: strategies for enhancing the learner experience and quality of MOOCs. Gráinne Conole 
EDUCAUSE (2013). ds106: Not a Course, Not Like Any MOOC.

Ehlers, U. D., E. Ossiannilsson, et al. (2013). Week 1: MOOCs and Quality - Where are we - where do we go from here ...? MOOC Quality Project.

Glennie, J., K. Harley, et al. (2012). Open Educational Resources and Change in Higher Education: Reflections from Practice. Vancouver, Commonwealth of Learning/UNESCO.

Jarvis, P. (2004). Adult education and lifelong learning. London, RoutledgeFalmer.

Jenkins, H. (2009). Confronting the challenges of participatory culture: Media education for the 21 st century, Mit Pr.

Lévy, P. (1997). Collective intelligence: Mankind's emerging world in cyberspace, Perseus Books Cambridge, MA, USA.

Littlejohn, A. (2003). Reusing online resources: a sustainable approach to e-learning, RoutledgeFalmer.

Mayes, T. and S. De Freitas (2004). Review of e-learning frameworks, models and theories, JISC e-learning models desk study.

Nkuyubwatsi, B. (2013). The evaluation of Massive Open Online Course (MOOCs) from the learner's perspective. ECTEL, Paphos, Cyprus.

Oblinger, D. G. and J. Oblinger (2005). Educating the Net Generation, EDUCAUSE \%U http://routes.open.ac.uk/ ixbin/ hixclient.exe?_IXDB_=routes\&_IXSPFX_=g\&submitbutton=summary\&\%24+with+res_id+is+res19283.

Raban, C. (2007). "Assurance versus enhancement: less is more?" Journal of Further and Higher Education 31(1): 77 - 85.

Reich, J. (2013). Is a MOOC a textbook or a course? EdTech researcher. 2013.

Rennie, F. and T. Morrison (2012). e-Learning and social networking handbook - resources for higher education. London, Routledge.

Sawyer, R. K. (2006). The Cambridge handbook of the learning sciences, Cambridge University Press \%@ 0521845548, 9780521845540.

Sharpe, R. and H. Beetham (2010). Rethinking learning for the digital age: how learnes shape their own experiences. London, Routledge.

Thorpe, M. (2002). From independent learning to collaborative learning: New communities of practice in open, distance and distributed learning. Distributed learning: Social and cultural approaches to practice. M. Lea and K. Nicoll. London, RoutledgeFalmer: 131-151.

MOOCs as disruptive technologies: strategies for enhancing the learner experience and quality of MOOCs. Gráinne Conole 
Traxler, J. (2005). Mobile learning: A Handbook for Educators and Trainers. Abingdon, Routledge.

Wikipedia (2012). "Massive Open Online Courses." from http://en.wikipedia.org/wiki/Massive_open_online_course. 